\title{
Discourse Analysis in Teaching Professional Communication
}

\author{
Wang $\mathrm{Mo}^{1}$, Juliya V. Ageeva ${ }^{2} \&$ Lin $\mathrm{Mei}^{3}$ \\ ${ }^{1}$ Department of RCI Institute of Philology and Intercultural Communication, Kazan Federal University, Kazan, \\ Tatarstan, Russia \\ ${ }^{2}$ Institute of Philology and Intercultural Communication, KFU, Kazan Federal University, Kazan, Tatarstan, Russia \\ ${ }^{3}$ Xi'an University of Foreign Languages, Xi' an International Studies University, Xian, China \\ Correspondence: Wang Mo, Department of RCI Institute of Philology and Intercultural Communication, Kazan \\ Federal University, Kazan, Tatarstan, Russia. E-mail: 522127385@qq.com
}

Received: September 2, 2020

Accepted: October 22, 2020

Online Published: October 31, 2020

doi:10.5430/ijhe.v9n8p29

URL: https://doi.org/10.5430/ijhe.v9n8p29

\begin{abstract}
The goals of the article's authors are: to justify the need to teach students the skills of professional communication in a foreign language on the basis of a text-oriented approach; to demonstrate the possibility of conducting this type of training in reference to the discourse analysis of a particular institutional area. Achievement of the goals is ensured by a set of the following theoretical, empirical, and experimental. Analysis, synthesis, a generalization of scientific and methodological works on the research topic; discourse analysis (method) of institutional communication; methods for collecting and accumulating data; experiential learning, implementation into practice. The article presents the results of the study: teaching professional communication through the use of professional texts with due regard for the discourse analysis of the corresponding communicative situation is grounded; the significance of the text-oriented approach in teaching international students the language of their university major is estimated; ways of developing the respective speech competencies are exemplified. The results presented in this article could be instantaneously applied in the learning process and eventually in the job search. The conclusions would be demanded in theoretical courses on the methodology of teaching foreign languages, special courses on the university major's language, etc.
\end{abstract}

Keywords: professional communication, the language of the university major, discourse, text-oriented approach, CV as a genre

\section{Introduction}

Teaching international students the Russian language is on the permanent research agenda of scholars and educators whose numerous works concern various aspects of students' Russian-language training. Advanced methods of language training for foreigners are actively studied (Makleeva et al., 2018; Varlamova et al., 2014; Khabibullina et al., 2019), including the text-oriented approach as one of the leading principles of teaching Russian as a Foreign Language (hereinafter referred to as RFL). Mastering the university major's language and gaining professional communication skills occupy an essential place in learning, since the Russian language for international students is a communication tool in the academic environment and a means of communication in the future profession. For this reason, the presented study is relevant and well-timed.

It is noteworthy that international students are taught the Russian language, precisely, Russian professional communication concerning those professional discourses associated with their specialization. Simultaneously, discourse as "the central moment of human life in the language" (Tlekhatuk, 2015), is closely related to the concept of a "text": it is a phenomenon that occurs in interaction, a fixed result of communication.

A curriculum vitae (CV) is one of the types of professional texts. Its uniqueness as text material for teaching foreigners communication in the university major is in social characteristics of communication participants: in each CV, both the writer and the reader are representatives of a particular professional sphere (recruitment, construction, agriculture, education, medicine, etc.). It results in compliance with specific rules and norms of communication inherent in a particular social sphere. 
The article attempts to capture the essence of the concept of professional discourse and indicate the discursive features of $\mathrm{CV}$ as a type of text, an effective tool for teaching international students professional communication in Russian.

\section{Methods}

The following research methods were used to further this goal: problem statement, analysis of specialized courseware, heuristic methods, a comparative method, etc.

\section{Results and Discussion}

Modern linguistics does not witness global studies regarding the development of a general concept of professional discourse (PD). The term has multifarious definitions in research papers. For example, E.I. Golovanova considers PD as "verbally mediated communication, controlled interaction of professionally active subjects characterized by a certain set of norms, stereotypes of thinking and behavior" (Golovanova, 2013). L.S. Beilinson understands PD as "communication between professionals or with those who seek advice or professional help" (Beilinson, 2009). In some cases, PD is called "the language created by professionals with special education to perform actions in the workplace" (Kochemasova \& Voronina, 2018). The authors of the article follow the opinion that PD is a unique form of discursive practice that exists within a certain professional sphere.

Besides the linguistic concept of professional discourse, there is a relevant term, institutional discourse. Linguists have made attempts to distinguish two above-referenced concepts. The analysis of corresponding Russian and international studies undertaken by A.O. Stebletsova unveiled that the Russian theory of discourse considers the institutional discourse a broad concept and refers to professional discourse as its sub-type (Stebletsova, 2015). It should be explained that the institutional discourse is a specialized clichéd type of communication that takes place between representatives of social groups, institutions, or between institutions and people who transform their social opportunities within the framework of established institutional settings. "In this case, the two parties of communication may not know each other. Nevertheless, they should build communication following the rules of conduct accepted in the society" (Karasik, 2002). In our experience, the majority of scholars regard professional discourse as a type of institutional discourse. The following factors should not be neglected in defining the type of institutional communication: status and roles of participants, a communication purpose, a prototype communication venue. Consequently, fundamental constituents for determining professional discourse are the communication participants (at least one of them is a specialist in a particular field). Secondly, the purpose of communication is to fulfill the task by communicants to obtain a socially significant result. It is the purpose of professional activity that determines the topic of communication and means of verbalization. Participants should behave within the framework of the rules and standards adopted in the professional environment to accomplish the goal. Thirdly, the prototype communication venue is a workplace that ensures social significance to the communication participants' activities (Baguant, 2019: Ponomarenko et al).

From this perspective, we put forward the following definition of the term "professional discourse": professional discourse is one of the types of institutional discourse, communication of professionals as representatives of social groups in order to perform socially significant tasks in the workplace (Wang, 2019). In this case, at least one of the subjects should have special training, which, in our opinion, is the clearest sign of this type of communication.

According to V.I. Karasik, institutionalization is gradual: "Institutional discourse is stemmed from communication between a basic pair of communication participants unequal in status. A contract between the representative of the institute and a person who is not related to this institution is on the periphery of institutional communication" (Karasik, 2002). The "pure" professional discourse includes such types as recruitment discourse, educational discourse, etc.

As previously noted, discourse is closely related to the concept of the text. The discourse theory regards this term as a linguistic activity, and its result is reflected in the form of a text (Kibrik, 2003). E.S. Kubryakova and O.V. Alexandrova (1997) have expressed a similar opinion that the discourse is a cognitive process associated with speech activity; the text is the result of this activity in a certain complete form. In the view of N.D. Arutyunova, the discourse is "a coherent text in conjunction with extra-linguistic, pragmatic, social, cultural, psychological and other factors" (Arutyunova, 1990). According to N.S. Bolotnova, with respect to the text in its broad sense, text generation depends on extra-linguistic factors and linguistic factors (Bolotnova, 1999). In the course of the study, it was determined that teaching a foreign language, including Russian, on a textual basis is a key element for ensuring a better quality of language teaching (Ageeva \& Wang, 2019). Considering the foregoing, it is fair to suggest that teaching Russian professional communication to international students should become more effective if it is based on professional 
textual material excerpted from a certain institutional discourse type.

Let us have a look at this fact in the context of modern recruitment discourse (the field of selecting and appointing suitable candidates for a job) (Yapparova et al., 2017). Recruitment is a professional discourse in its classical sense. Its participants (an addresser and a target recipient) are specialists in certain occupational fields. The recruitment discourse analysis emphasizes its two main textual genres, namely, a job announcement and a CV. This article dwells on the $\mathrm{CV}$, since writing CVs' communicative skills are essential for all students - prospective employees. In the process of mastering skills to write the $\mathrm{CV}$, students acquire language skills. Coincidently, by working with such texts, they can gain knowledge that will boost communication in their native language, e.g., considering information vital for $\mathrm{CV}$ (what the optimal way to present oneself to a future employer is, how to get the job).

Modern dictionaries provide several definitions of the CV. In this study, the CV is understood as a text, a document containing information about education, professional skills, experience, etc. submitted by the applicant for an open vacancy following the employer's requirements. The teacher should introduce students to linguistic and extra-linguistic features of this discourse genre and explain that competent writing of a $\mathrm{CV}$ is one of the most significant stages of work placement. Having familiarized me with the job announcement, the prospective employee should start communication and create a professional text. It should be stressed that students in the Russian language classes are meant to step into an applicant's role and learn to present themselves effectively in limited frameworks of the standard text.

Efficient training in writing a CV includes introducing students to CV's standard structure, components, genre specifics, basic language features, requirements for its content, etc. In general, the following components are invariably presented: a title of the document, a date, personal information of the applicant. During the research, it was concluded that students should study the real CVs (for example, from the websites of recruitment agencies) with a concentration on requirements, professional skills, and cases with a lack of experience. Speech models, material for the analysis, relevant vocabulary, and grammar structures are implemented into practice through texts of real documents.

Let us look at the $\mathrm{CV}$ that was chosen as a representative sample of this type of text:

\section{Teacher's CV}

\section{Olga Panchenko}

DOB: 25.10.1979

City: Moscow

Tel.: 7 (000) 0000000

E-mail: panchenkoo-000@gmail.com

Purpose: to apply for a position of a teacher

\section{Education:}

September, 2006 - June, 2011 Moscow City University named after O.P. Krasnov, Faculty of Biology, concentration in Biology, Master's degree (full-time education)

\section{Additional education}

April, 2005 - June, 2005 - advanced training in Chemistry

October, 2010 - participation in trainings "Modern Psychology and Education"

\section{Professional Experience:}

A teacher of Biology: July 2001 - January 2011, Gymnasium \#36, Moscow city

Responsibilities:

- $\quad$ organization of lab sessions

- control over the knowledge of students

- trainings for Olympiads

Achievements: 2008, 2010 - students won the regional Olympiad in Biology

\section{Professional skills:}

- confident computer user; - skills of a tutor;

- experience in class supervision; 
- commitment;

- mastering business etiquette;

- command of languages: Russian - fluent, English - beginner

Personal qualities: responsibility, timeliness, high level of self-discipline, stress tolerance, patience, interpersonal and observation skills, an ability to get on well with children

Additional information:

Marital status - married

Children: yes

URL:

https://csri.ru/raznoe/rezyume-pedagoga-obrazec-sostavleniya-dlya-uspeshnogo-priema-na-rabotu-kak-pravilno-opis at-professionalnye-navyki-i-obyazannosti.html (date of access - 21.03.2020)

The template contains necessary structural components of the CV: full name, contacts, education, work experience, professional skills, personal qualities, additional information. In Russian as a Foreign Language classes, international students can get acquainted with the types of CVs, the main constituent points, and the algorithm for its compiling using similar textual material. The text-oriented approach considers the text as the initial and final unit of training, material for teaching professional communication.

Additionally, the teacher should present some extra-linguistic competencies: what personal information can/cannot be disclosed; how to present oneself without work experience.

\section{Summary}

Thus, the study determined the discursive features of the CV: the communicative purpose is to obtain the position; the status of the author is a candidate for an open vacancy, the target recipient is the employer; the discursive event is search for a job; compliance with a certain standard in organizing the text - special requirements to text design; language requirements - official business style.

While learning the language of their university major through a professional text (in this case, CV), international students have an opportunity to master language knowledge by developing practical skills in writing a CV, to realize their professional interests and creative abilities. It is crucial for the socialization of the young generation representatives.

Undoubtedly, the text-oriented approach occupies a special place in pragmatic approaches to teaching RFL in a special field. It determines the use of authentic texts (CV) as a verbally recorded result of communication in a specific professional environment. In this regard, the study findings may be applied in "Russian Language: Professional Speech", "Business Language," and other classes with international students. Moreover, they could be taken into account when designing training materials on RFL.

\section{Conclusions}

Finally, CV, as a professionally-oriented educational text, has multiple benefits and advantages. Nevertheless, despite the main components and discursive features described in the article, the achievement of better results in teaching international students the language of their primary and communicating in the professional field requires solving several issues associated with the speech genre of the CV: in particular, in-depth studies of CVs in professional discourses (following the concentration of studies), review of the fundamental textual characteristics of the CV. These features define the direction of further research. Accordingly, the well-known principle of teaching foreign languages formulated by E.I. Passov - "teaching culture through language and language through culture" (Passov, 2000) - can be rephrased as follows: teaching professional communication through language and, vice versa, teaching language through professional communication. It involves a bilateral process of mastering communicative skills in an institutional environment.

\section{Acknowledgements}

The work is performed according to the Russian Government Program of Competitive Growth of Kazan Federal University. 


\section{References}

Ageeva, Y., \& Wang, M. (2019). Professionally-Oriented Education: Profile of Textbook in the University Major. Proceedings of II World Congress "EAST-WEST: THE INTERSECTION OF CULTURES" at Kyoto Sangyo University Kyoto, 2, 35-358.

Arutyunova, N. D. (1990). Diskurs [Discourse]. Lingvisticheskiy entsiklopedicheskiy slovar, 136-137.

Baguant, N. D. (2019). Integration of Information and Communication Technologies in Teaching by Female Academic Teaching Staff in the Higher Education Sector in Mauritius. International Journal of Higher Education, 8(5), 4-11. https://doi.org/10.5430/ijhe.v8n5p56

Beilinson, L. S. (2009). Professional discourse as the subject of linguistic investigation. ВОЛГОГРАДСКОГО ГОСУДАРСТВЕННОГО УНИВЕРСИТЕТА, 145.

Bolotnova, N. S. (1999). Fundamentals of Text Theory: A Handbook for Teachers and Students in Philology. Tomsk: Izd-vo Tom. gos. ped. un-ta.

Golovanova, E. (2013). Professional Discourse, Sub-discourse, Genre of Professional Communication: Correlation of Concepts. CSU Bulletin. Ser. Philological Sciences. Arts, 1(292), 32-35.

Karasik, V. I. (2002). Language circle: personality, concepts, discourse. Volgograd: Peremena, 477.

Khabibullina, E. V., Shtyrlina, E. G., \& Guzi, L. (2019). Methods of Teaching the History of Language to Foreign Students. International Journal of Higher Education, 8(7), 74-78. https://doi.org/10.5430/ijhe.v8n7p74

Kibrik, A. (2003). Discourse Analysis in Cognitive Context. doctoral thesis-report: 10.02.19. Moscow: Institute of Linguistics of the RAS. 280-295.

Kochemasova, D., \& Voronina, E. (2018). Professional Discourse. Vestnik of the Mari State University, 12(2), 146-151. https://doi.org/10.30914/2072-6783-2018-12-3-146-151

Kubryakova, E. S., \& Aleksandrova, O. V. (1997). Types of space, text, and discourse. In Categorization of the World: Space and Time. Proceedings of a scientific conference. Moscow: Dialogue MSU (pp. 19-20).

Makleeva, E. A., Akhmetzyanova, L. M., \& Zhike, Y. (2018). Integration of teaching methods and principles of selection of language material in classes of Russian as a foreign language. Ad alta-journal of interdisciplinary research, 8(1), 172-174. https://doi.org/10.36941/ajis-2019-0053

Passov, E. (2000). Framework Program of Communicative Foreign Language Education. Moscow: Prosvescheniye.

Stebletsova, A. (2015). National Features of Business Discourse in Higher Education (based on English and Russian written communication). doctoral thesis: Voronezh.

Ponomarenko, E., Mikhailov, E., Myasnikov, N., Vyazov, L., Ershova, E., \& Blinnikov, M. Bolshie algashi hillfort in the lower Sura region.

Tlekhatuk, S. (2015). Economic Discourse as a Verbalization Fragment of Human Experience: Socio-Cognitive Aspect. The Bulletin of the Adyghe State University Series 2: Philology and the Arts, 1(152), 94-99.

Varlamova, M., Miftakhova, A., \& Palekha, E. (2014). Visual Listening" In Theory And Practice Of Effective Foreign Language Teaching. In INTED2014 Proceedings (pp. 7129-7133). IATED.

Wang, M. (2019). Announcement as a Genre of Professional Discourse. Journal "Philology and Culture", 1(55), 18-21. https://doi.org/10.26907/2074-0239-2019-55-1-18-21

Yapparova, V. N., Ageeva, J. V., \& Adamka, P. (2017). Endurance Testing: Communicative Stress Tactics Of Interviewers In Job Interviews. Ad Alta-Journal Of Interdisciplinary Research, 7(2), 148-150.

\section{Copyrights}

Copyright for this article is retained by the author(s), with first publication rights granted to the journal.

This is an open-access article distributed under the terms and conditions of the Creative Commons Attribution license (http://creativecommons.org/licenses/by/4.0/). 